\section{Luminous targets: Visibility fluctuations modified by similar verbal responses*}

\author{
DON DONDERI and BARBARA MILLER \\ McGill University, Montreal, Quebec, Canada
}

Ss reported visibility fluctuations in a luminous target consisting of small, medium, and large circles. Each $\mathbf{S}$ had previously learned a response to each of the three circles. The experimental group learned two words which were free aseociates of each other and a third unrelated word. The control group learned three unrelated words. Concurrent visibility for the pair of circles associated with related words was greater than for the pairs associated with unrelated words. Thus word associations influence perception of stimuli for which the words are responses.

Although perception ordinarily depends upon the stimulus, other influences can be demonstrated when the stimulus is reduced in strength or complexity. A phenomenon which illustrates these influences is the subjective disappearance and reappearance of a set of luminous visual stimuli viewed against a dark background. The pattern of disappearances can be changed when identical responses are learned for some of the stimuli (Donderi \& Kane, 1965). This is interpreted to mean that the phase cycle representing a common response correlates neural activity in phase cycles representing its stimuli (Hebb, 1949). Other evidence that learned associations affect perceptual organization has been obtained by McKinney $(1963,1966)$ and by Tees and More $(1967 \mathrm{a}, \mathrm{b})$ using similar techniques.

Since identical responses influence stimulus disappearances, two related but not identical responses might also influence the disappearances albeit less strongly. Donderi and Kane assume that an identical response adds a "common element" to both neural stimulus representations, providing a phase cycle linkage between them which maintains their coincident activity (Hebb, 1949, p. 130). The concept of "common elements" can also be applied to related response words. The proportion of "common elements" in two words can be assumed to increase as the frequency with which they are given as free associates of each other increases.

Following this reasoning, one set of three response words was chosen so that two words were frequent free associates of each other and the third was an associate of neither. Another set of words was chosen so that none was a close associate of any other. The response words were then paired with

*This research was supported by grants trom the National Research Council of Canada and from the Defence Research Board of Canada (No. 9401-11). three stimulus circles of different size in a paired-associates learning task. Afterwards, the three circles were presented together as luminous stimuli and their observed disappearances and reappearances were recorded. A significant coincidence between the visibility states of circles paired with evidence that related responses influence perceptual organization.

\section{METHOD \\ Stimuli}

Stimuli were three circles 0.65 , 1.27 , and $1.91 \mathrm{~cm}$ in diam. During learning, they were white on black $7.6 \times 12.7 \mathrm{~cm}(3 \times 5$ in.) cards. In the darkroom, they were luminous at $0.03 \mathrm{c} / \mathrm{m}^{2}$. The source was an incandescent bulb diffused by onion skin paper. In both tasks stimuli were viewed at eye level $56 \mathrm{~cm}$ distant, and subtended visual angles of $0 \mathrm{deg}$ $38 \mathrm{~min}, 1 \mathrm{deg} 15 \mathrm{~min}$, and $1 \mathrm{deg}$ $53 \mathrm{~min}$.

\section{Responses}

There were two response sets, each of three words. The experimental set was boy, girl, fish and the control set was light, goon, rough. Boy and girl are free associates but none of the others are. Boy was the most frequent associate to girl ( $p=.36$ to .82 ) in all eight studies summarized by Shapiro and Palermo (1968), whose review furmished the association data. Girl was the most frequent associate to boy $(p=.61$ to .82$)$ in all nine studies summarized. The most frequent response to fish was water ( $p=.11$ and .13 in two studies). The most frequent associate for light was dark ( $p=.21$ to .59 in 10 studies). One study gave bulb ( $p=.29)$ as the most frequent response. The most frequent response to rough was smooth in all seven studies $(p=.23$ to .56$)$. Light, boy, girl and fish occurred at least 100 times per million in the Thorndike-Lorge (1944) count, rough appeared at least 50 times per million, the related words would be considered and goon did not appear as often as 4 times per 18 million words. This ranking agrees with West's (1953) word count.

\section{Subjects}

Twenty-four English-speaking high school and college student volunteers ( 10 women) were paid for participating in a series of vision experiments. One $\mathbf{S}$ did not complete this experiment. They were assigned randomly to the control and experimental groups and to the words-circles combinations within each group, with the restriction of equal $\mathbf{N}$ in each condition. The learning and darkroom tasks were presented as unrelated parts in this series of experiments.

\section{Learning Task}

The Ss learned to associate one of the three words to each of the three circles. The experimental group $(\mathrm{N}=11)$ learned boy, girl, and fish, and the control group $(N=12)$ learned light, goon, and rough. Words and circles were paired in a Latin square within the experimental and control groups. Three Ss were assigned randomly to each circle-word combination, but one $S$ in the originally assigned experimental group of $12 \mathrm{Ss}$ failed to complete the experiment. The design is illustrated in Table 1.

Stimuli were presented manually in a single predetermined random order. Each presentation lasted about $1 / 2 \mathrm{sec}$, with an interval of about $3 \mathrm{sec}$ between each presentation. $E$ said "right" or "wrong" after each response. Each stimulus circle was shown 40 times, giving a total of $\mathbf{1 2 0}$ presentations.

\section{Darkroom Task}

The three luminous circles were displayed $56 \mathrm{~cm}$ distant at eye level perpendicular to the S's line of sight. Their centers were located $2.8 \mathrm{~cm}$ from a luminous fixation point and equidistant from each other at 0,120 , and 240 deg. $S$ was seated at a table, his head supported by a chinrest. Three pushbuttons were on the table in front of him. Each operated a separate pen on an event recorder.

An eye patch covered S's nonpreferred eye. $\mathbf{S}$ dark-adapted for $20 \mathrm{~min}$ while listening to a tape recording instructing him how to respond to the observed fluctuations in visibility. He was told to press the button corresponding to each circle as long as it was visible. Ss practiced using the buttons by following a tape-recorded sequence of imaginary visibility configurations equally balanced among all possible patterns. Following the adaptation and 
Table 1

Duration of Visual Coincidence for Clrcle and Response Pairs: Experimental Group

\begin{tabular}{|c|c|c|c|c|}
\hline \multirow[b]{2}{*}{$\mathbf{S}$} & \multicolumn{3}{|c|}{ Proportional Duration } & \multirow{2}{*}{$\begin{array}{c}\text { Total } \\
\text { Duration } \\
\text { (Sec) }\end{array}$} \\
\hline & Boy-Girl & Boy-Fish & Girl-Fish & \\
\hline $\begin{array}{l}1 \\
2 \\
3 \\
4\end{array}$ & $\begin{array}{l}511 \mathrm{ml} \\
\mathbf{5 0 8} \\
\mathbf{7 4 0} \\
\mathbf{6 2 7}\end{array}$ & $\begin{array}{l}271 \mathrm{sm} \\
364 \\
043 \\
168\end{array}$ & $\begin{array}{l}218 \text { sl } \\
138 \\
217 \\
209\end{array}$ & $\begin{array}{l}48 \\
39 \\
12 \\
67\end{array}$ \\
\hline $\begin{array}{l}5 \\
6 \\
7 \\
8\end{array}$ & $\begin{array}{l}516 \mathrm{sm} \\
855 \\
816 \\
412\end{array}$ & $\begin{array}{l}153 \text { al } \\
060 \\
082 \\
247\end{array}$ & $\begin{array}{l}331 \mathrm{ml} \\
085 \\
102 \\
341\end{array}$ & $\begin{array}{r}62 \\
117 \\
153 \\
41\end{array}$ \\
\hline $\begin{array}{r}9 \\
10 \\
11\end{array}$ & $\begin{array}{l}462 \mathrm{sl} \\
623 \\
555\end{array}$ & $\begin{array}{l}308 \mathrm{ml} \\
145 \\
167\end{array}$ & $\begin{array}{l}230 \mathrm{sm} \\
232 \\
278\end{array}$ & $\begin{array}{l}65 \\
34 \\
27\end{array}$ \\
\hline
\end{tabular}

Note-Circle pairs indicated as follows: $s m=s$ mall-medium, sl $=$ small-large, $m l=m e d i u m-l a r g e$ Proportional durations $=$ entries $\times 10^{-3}$

instruction, Ss viewed the stimulus for $5 \mathrm{~min}$ in one orientation and for $5 \mathrm{~min}$ in a different orientation. During the first $5 \mathrm{~min}$, the medium (1 deg $15 \mathrm{~min}$ ) circle was at $0 \mathrm{deg}$, the large circle (1 deg $53 \mathrm{~min}$ ) at $120 \mathrm{deg}$, and the small circle ( $0 \mathrm{deg} 38 \mathrm{~min}$ ) at $240 \mathrm{deg}$. During the second $5 \mathrm{~min}$, the position of the small and large circles was reversed. There was a 10 -min rest period in the dark between the sessions.

Data Analysis

There are eight visibility states in the set of three circles. These are: all circles visible, all invisible, two visible and one invisible (three possibilities), and two invisible and one visible (three possibilities). Two circles are in visual coincidence when either both are visible or both are invisible exclusive of the third. The frequency or the total duration of visual coincidence of circle pairs accounts for six of the eight visibility states. The other two states, all three circles either visible or invisible, contain no information about the differential visual coincidence of pairs of circles. They were ignored. The results for each pair of circles from each $S$ were expressed as a proportion of the total duration or frequency of all three pairs for that $S$. The total duration data for each $S$ was retained and is also presented in Table 1.

\section{RESULTS}

Learning Task

No $S$ required more than 15 trials before responding correctly. Thus, all can be considered to have reached the asymptotic performance permitted by the 120 trials.

\section{Darkroom Task}

The effect of the response word pair boy-girl was to increase the visual coincidence of every pair of circles associated with them (Table 1). The proportional duration of visual coincidence was higher for the circles associated with boy and girl than for either of the other two pairs, boy-fish and girl-fish, for all 11 of the Ss in the experimental group. But the most coincident pair in the control group was not always associated with a particular set of response words. The circles associated with light-goon were more coincident for 2 Ss (mean proportion $[\bar{p}]=.331$ ), with light-rough for $4(\mathrm{p}=.326)$, and with goon-rough for the remaining $6 \mathrm{Ss}$ $(\bar{p}=.346)$. Visual coincidences based on frequencies give the same results. The total frequency in the experimental group ranged from 11 to 105 , and the visual coincidence was always greatest for the circles associated with boy-girl. Control-group frequencies ranged from 12 to 70 , and circles associated with each of the three word pairs were most coincident for 4 of the $12 \mathrm{Ss}$.

The prior probability that coincidences of circles associated with boy-girl would be greater than the other two circle pairs is one-third. On this assumption, the exact probability of the obtained result is $5.6 \times 10^{-6}$ for both duration and frequency data. The distribution of either duration and frequency coincidences in the control group is not significantly different from that expected under the prior assumption of equal probability.

Afterwards, the experiment was explained to each $S_{1}$ who was asked specifically if he had assumed any connection between the leaming and the darkroom task. No S said that he had assumed any connection between them.

\section{DISCUSSION}

In Hebb's (1949) theory, one phase cycle representing a concept or percept can share cell assemblies with another one. This is how an increase in visual coincidence with increased similarity between pairs of stimuli was explained (Donderi, 1966). Our present results indicate that responses are also organized as phase cycles. Two responses integrate the stimulus-based phase cycles with which they are associated, to the degree that the response phase cycles share cell assemblies. This correlates with how frequently the response words are free associates of each other.

Similar phenomena (Donderi \& Kane, 1965) have been explained as due to attention (Gibson, 1969, p. 72). Prior instructions do change the pattern of luminous stimulus disappearances (McKinney, 1966). But the term "attention" applied to this type of result means only that something other than common responses or stimulus pairing also influences the disappearance pattern. In our experiment, if $S$ was paying attention, he was attending to two circles with related responses. Thus our explanation for attention is also that it depends on the integration of phase cycles with common cell assemblies.

Finally, Neisser (1967, p. 80) explains McKinney's result by suggesting that $S$ reports quite unconsciously what he assumes $E$ expects him to report. But this did not happen in our experiment, because no $S$ had any idea what $E$ wanted him to report.

\section{REFERENCES}

DONDERI, D. C. Visual disappearances caused by form similarity. Science, 1966 , 152, 99-100.

DONDERI. D. C., \& KANE, E. Perceptual learning produced by common responses to different stimuli. Canadian Journal of Psychology, 1965, 19, 15-30.

GIBSON, E. J. Princlples of perceptual learning and development. New York: Meredith, 1969.

HEBB, D. O. Organization of behavior. New Youk: Wiley, 1949 .

M CKINNEY, J. P. Disappearance of luminous designs. Science, 1963, 140, 403-404.

McKINNEY, J. P. Verbal meaning and perceptual stability. Canadian Journal of Psychology, 1966, 20, 237-242.

NEISSER, U. Cognitive psychology. New York: Appleton-Century, 1967.

SHAPIRO, S, D. \& PALERMO, D. S. An atlas of normative free association data. Psychonomic Monograph Supplements, $1968,2(12$, Whole No. 28).

TEES, R. C., MORE, L. Effect of amount of perceptual learning upon disappearances observed under reduced stimulation conditions. Perception \& stimulation conditions, Perception

TEES, R. C., \& MORE, L. Visual disappearances under simplified stimulus conditions caused by auditory perceptual leaming. Perception \& Psychophysics, $1967 \mathrm{~b}, 2,627-629$.

THORNDIKE, E. L. \& LORGE, I. The teacher's word book of 30,000 words. New Yodk: Bureau of Publications, Teachers College, Columbia University, 1944.

WEST, M. (Ed.) A general service list of English words. London: Longmans, Green, 1953.

(Received for publication June 15, 1971.) 